\title{
APPLICATION OF THE NRCS CN METHOD (NATURAL RECOURSE CONSERVATION SERVICE CURVE NUMBER METHOD) FOR CALCULATING THE MAXIMUM RUNOFF
}

DOI: https://doi.org/10.18509/GBP210495z

UDC: 502.175:556.166.04(497.2)

\author{
Daniela Zlatunova \\ Sofia University “St. Kliment Ohridski”, Bulgaria
}

\begin{abstract}
The NRCS - CN method for calculating the maximum runoff is widely used in hydrological practice due to its easy adaptation and application. The method is based on the perception that catchment conditions (soil cover, land use and climatic conditions) can be expressed by the number of a territorial unit called the $\mathrm{CN}$ curve. The main factors that determine the numbers of the $\mathrm{CN}$ curves are the hydrological soil group, land use, the method of soil cultivation, the hydrological conditions and the previous soil conditions.

In connection with this the purpose of this publication is: to calculate the maximum runoff during the flood occurred in the period 31.07. - 02.08.2014 on the Scut River near the town of Mizia by the NRCS - CN method.

For this purpose, a Geographic Information System (GIS) has been created, which includes the following layers: soil types and subtypes (soil map in M: 1: 200000), land use (map of restored property, 2013), average rainfall for the period 31.07.2014 2.08.2014 (information from NIMH and EA "Fight against hail"), slopes (digital terrain model, 2011).

The main results of the conducted research are the calculated volume and maximum runoff of the formed high wave, which flooded the town of Mizia.
\end{abstract}

Keywords: maximum runoff, NRCS - CN method, flood, GIS

\section{INTRODUCTION}

The NRCS - CN method is widely used in the hydrological practice due to its easy adaptation and application. The method was developed in 1954 by the USDA Soil Conservation Service (Rallison 1980), and is described in the Soil Conservation Service (SCS) National Engineering Hand-book Section 4: Hydrology (NEH-4) (SCS 1985). The first version of the handbook containing the method was published in 1954. Subsequent revisions followed in 1956, 1964, 1965, 1971, 1972, 1985, and 1993. Since its inception, the method had the full support of a federal agency and, moreover, it filled a strategic technological niche. Thus, it quickly became established in hydrologic practice, with numerous applications in the United States and other countries. Experience with the runoff curve number continues to increase to this date. [5], [6] ,[7], [8] The method is based on the perception that conditions in the catchment (topsoil coverage, land use and climatic conditions) can be expressed by the number of a territorial unit called the $\mathrm{CN}$ curve. The main factors that determine CS curve numbers are hydrologic soil group, land use, soil treatment method, hydrological conditions and previous soil conditions Antecedent Moisture Condition (ARC) Classes . 
In this regard, the purpose of this publication is to calculate the maximum run-off during the flooding that occurred in the period 31.07. - 02.08.2014 of the Skat River in Mizia by NRCS - CN method. The subject of application of the method is the Skat River, in the town of Mizia, which stretches in the Western subarea of the Danube hilly plain and is the largest tributary of the Ogosta River. (Fig.1).

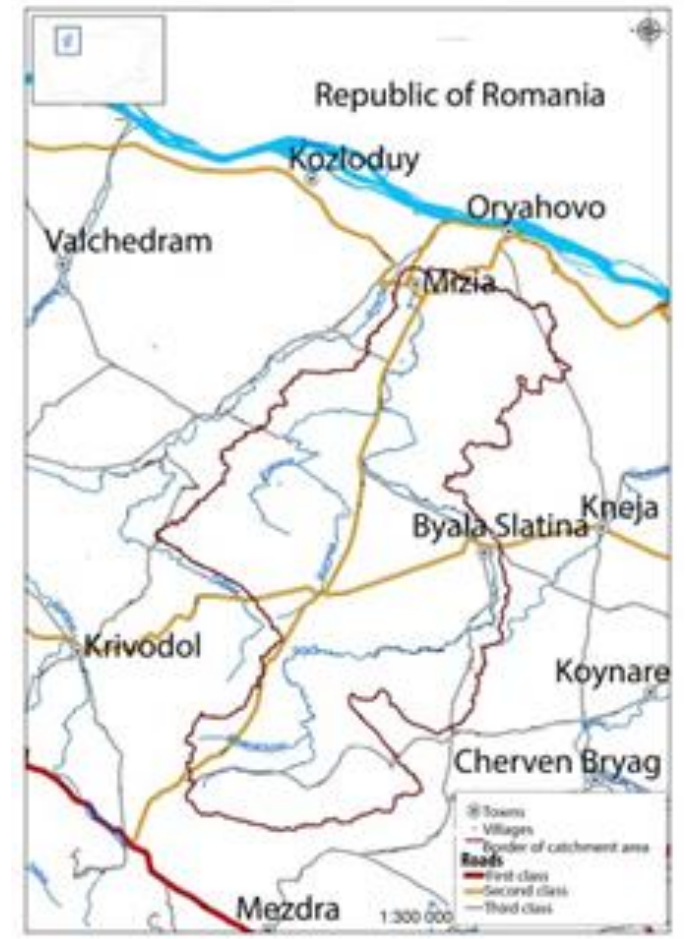

Figure 1. Geographical location of the Scat River catchment

\section{MATERIAL AND METHODS}

A database has been created for the application of NRCS - CN method on the catchment area of the Skat River. The database includes the following GIS layers: soil types and subtypes[4], land use[3], average rainfall for the period 31.07.2014-2.08.2014 [2], slope gradients, digital elevation model, 2011, CN values for each hydrological group and the corresponding moist soil conditions (ARC III), reported from [1]. For each CN polygon, the so-called maximum retention potential $-S$ (maximum potential infiltration of precipitation) ${ }^{14}$ and surface runoff $(\mathrm{Q})$ separately for each $\mathrm{CN}$ polygon, applying equation (1) and equation (2):

$$
\begin{aligned}
& S=\frac{25400}{C N}-254 \\
& Q=\frac{(P-0,2 S)^{2}}{(P+0,8 S)},
\end{aligned}
$$

where $S$ is the maximum potential infiltration $(\mathrm{mm}) ; C N$ is the curve number corresponding to a type of land use; $Q$ is a surface runoff $(\mathrm{mm})$ calculated for each $C N$ polygon; $P$ is precipitation $(\mathrm{mm})$.

\footnotetext{
${ }^{14}$ Displays this part of the precipitation that will infiltrate the soil with the relevant soil properties and land use type
} 
The corrections of the $C N$ values for polygons with gradients greater than or equal to 5 $\%$ shall be carried out by equations (3) and (4):

$$
\begin{gathered}
C N_{2 a}=C N_{2} X K \\
K=\frac{322,79+15,63(\alpha)}{\alpha+323,52},
\end{gathered}
$$

$C N 2 a$ is the adjusted $C N$ value; $C N 2$ is the NRCS-CN value for moist soil conditions III (AMC); $K$ is a coefficient; $\alpha(\mathrm{mm}-1)$ is the slope of a slope.

The weighted (heavy) surface run-off for each sub-basin is calculated by equation (5):

$$
\bar{Q}=\frac{\sum_{i}^{n} Q_{i} A_{i}}{A},
$$

Where $\bar{Q}$ is the calculated weighted surface runoff for a sub-basin in (mm); $\mathrm{Q}_{\mathrm{i}}$ is the calculated surface runoff for each $C N$ polygon in $(\mathrm{mm}) ; \mathrm{A}_{\mathrm{i}}$ is the area of each $C N$ polygon in $\left(\mathrm{km}^{2}\right)$.

\section{RESULTS AND DISCUSSION}

For the calculation of the maximum run-off, the following steps are performed sequentially:

Generation of hydrological soil groups and CN (soil - land use) map

For the definition of hydrologic soil groups (A, B,C D), the properties of soil types distributed in the Skat Basin are taken into consideration. In accordance with them, carbonate, typical black earths and alluviologic - meadow soils refer to hydrologic soil group A, leached black lands (weak, medium and strong) to hydrologic soil group B, degraded black lands - to group C and gray and dark gray forest soils to Group D.

Hydrologic soil group A includes soil types that have a low potential for surface runoff formation due to the high rate of infiltration of rainfall $(1,8-3,0 \mathrm{~m} / 24 \mathrm{~h})$. Group B includes soil types with medium low surface runoff formation potential due to average rainfall rate $(1,3-2,6 \mathrm{~m} / 24 \mathrm{~h})$. Group $\mathrm{C}$ includes soil types with medium high potential for surface run-off formation due to low rainfall infiltration rate $(0,9-1,6 \mathrm{~m} / 24 \mathrm{~h})$. The last hydrologic soil group D includes soil types with a high potential for surface runoff formation due to the very low rate of infiltration of rainwater $(0,09-0,03 \mathrm{~m} / 24 \mathrm{~h})$. The relative share of the individual soil groups in the basin of the Skat Is presented in Table 1 .

Table 1. Relative share of hydrological soil types

\begin{tabular}{|l|l|l|}
\hline $\begin{array}{c}\text { Hydrologic } \\
\text { soil types }\end{array}$ & \multicolumn{1}{|c|}{ Sq. $\mathbf{~ m}$} & \multicolumn{1}{|c|}{$\%$} \\
\hline A & 232,1 & 21,52 \\
\hline B & 424,3 & 39,35 \\
\hline C & 174,2 & 16,15 \\
\hline D & 247,8 & 23 \\
\hline Total area & $\mathbf{1 0 7 8 , 3 6}$ & $\mathbf{1 0 0}$ \\
\hline
\end{tabular}

About $22 \%$ of the soil types distributed in the Skat River basin fall into soil group A, while soil groups $C$ and D account for about $40 \%$ of soil types. The created GIS map of hydrologic soil groups is presented in Fig. 2. 


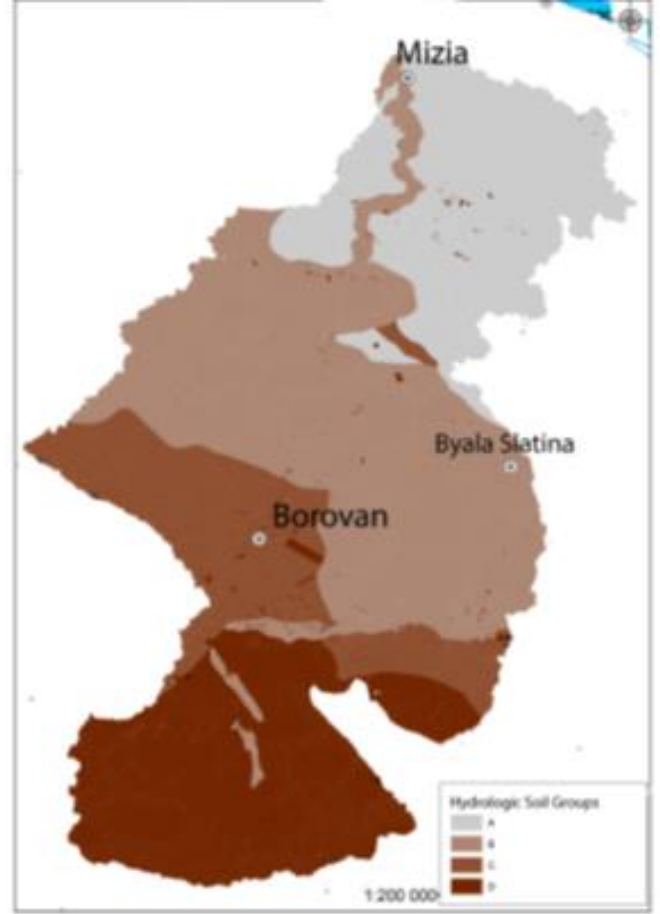

Figure 2: Hydrologic soil groups in the Skat River catchment

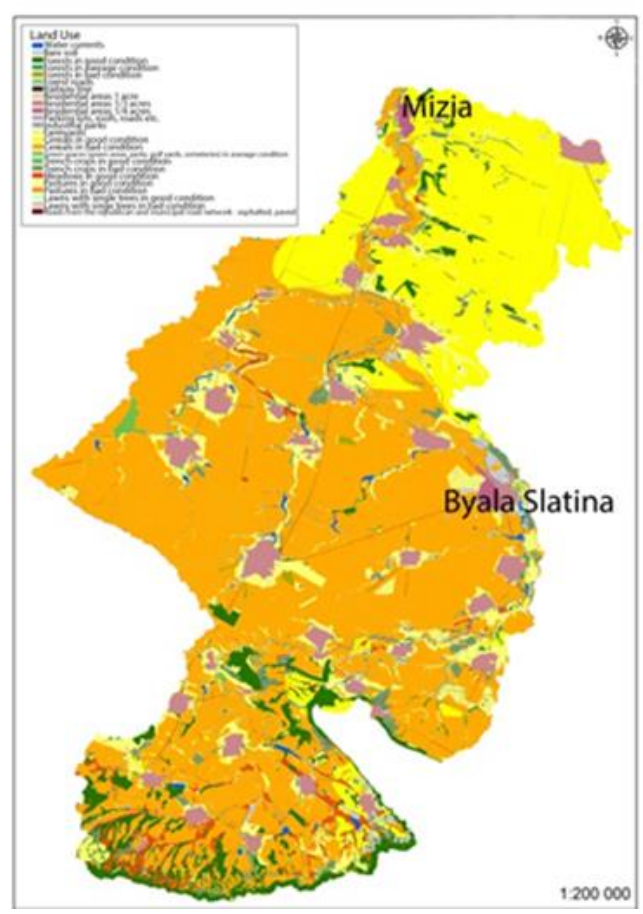

Figure 3: Land use in the Skat catchment

For the assessment of land use in the Skat River basin, the map of the restored property is used, relevance 2013[4] ${ }^{15}$. Its land use categories have been transformed into land use classes according to [3]. A total of 23 land use classes are allocated. The area of cereals is the biggest $(70.5 \%)$, pastures $(7.3 \%)$, forests $(5.3 \%)$ and residential areas $(5,3 \%)$ The relative share of the other classes is about $1 \%$ and less than $1 \%$. The land use classes are presented in Fig.3.

To create the CN GIS map, the information from the soil hydrologic group map (Fig. 1) and the land use map (Fig. 2) are transferred in ArcView. Using the Xtools tool, the CN map was created. The CN map includes new polygons formed on the basis of the land use map and the map of hydrologic soil groups. For each polygon, a $\mathrm{CN}$ value is determined. The $\mathrm{CN}$ values determined are for the so-called average Antecedent Moisture Condition (AMC II). Using standard tables, the transition to $\mathrm{CN}$ values for the wet Antecedent Moisture Condition (AMC III) has been made. The $\mathrm{CN}$ values thus determined are recalculated for all $\mathrm{CN}$ polygons which have an average slope gradient greater than or equal to $5 \%$. (Fig.4). The main regularity is related to the fact that lower $\mathrm{CN}$ values are corresponding to the hydrologic soil groups A and B. In terms of land use classes with the lowest value are forests in good condition, meadows in good condition, pastures in good condition and with the highest value respectively the land use classes - parking lots, residential areas, paved streets and roads. The recalculated $\mathrm{CN}$ values in accordance with equation (3) and (4) are presented in Fig. 4.

The $\mathrm{CN}$ map is a mosaic of $\mathrm{CN}$ values due to different land use. About $62 \%$ of the area of the basin has $\mathrm{CN}$ values between $81-90,25.5 \%$ between $91-90$ and $9.9 \%$ between 51 70 . Only $2.2 \%$ of the area has $\mathrm{CN}$ values below 50 . The analysis shows that cereal classes and perennial plants contribute the most to the formation of significant surface runoff.

\footnotetext{
${ }^{15}$ Provided by the Ministry of Agriculture, Food and Forestry
} 
Calculation of the average rainfall for the Skat river catchment.

The average rainfall in the Skat river catchment was calculated on the basis of the information from the Department of Weather Forecasts (NIMH) and the Hail Suppression Agency on the amount of rainfall for the period 31.07.2014-2.08.2014 (Fig. 5). To do this, the Thiessen method was applied. [1]

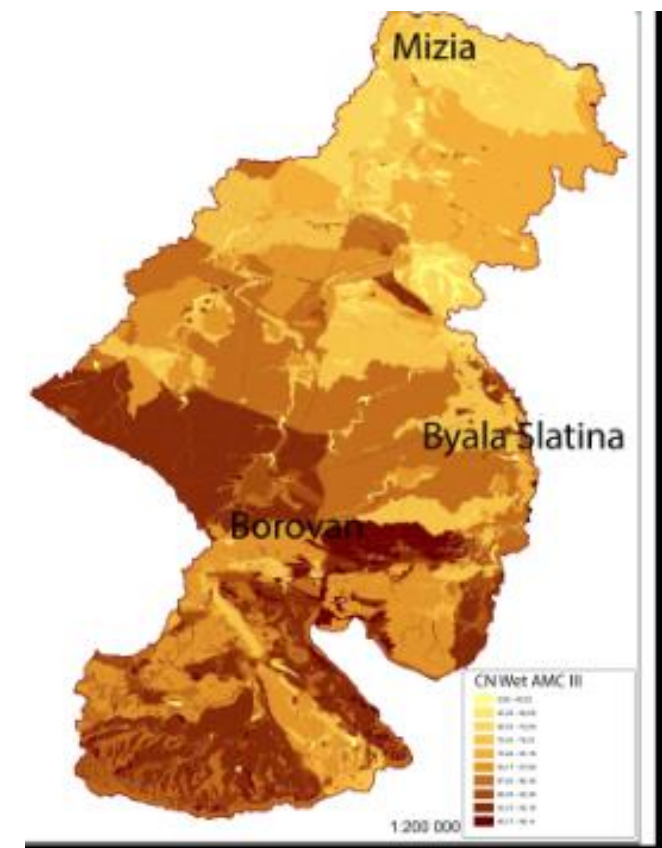

Figure 4: $\mathrm{CN}$ map of the Skat river catchment

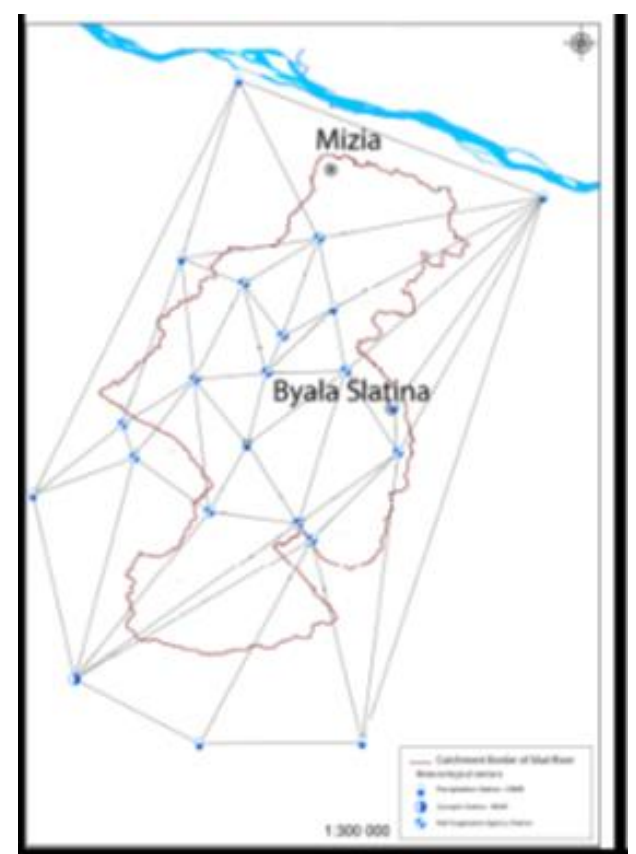

Figure 5: Location of stations and settlements and 24-hour rainfall amounts

The territorial distribution of precipitation is presented in Fig. 6 and the average rainfall is calculated at $114,331 / \mathrm{m} 2$.

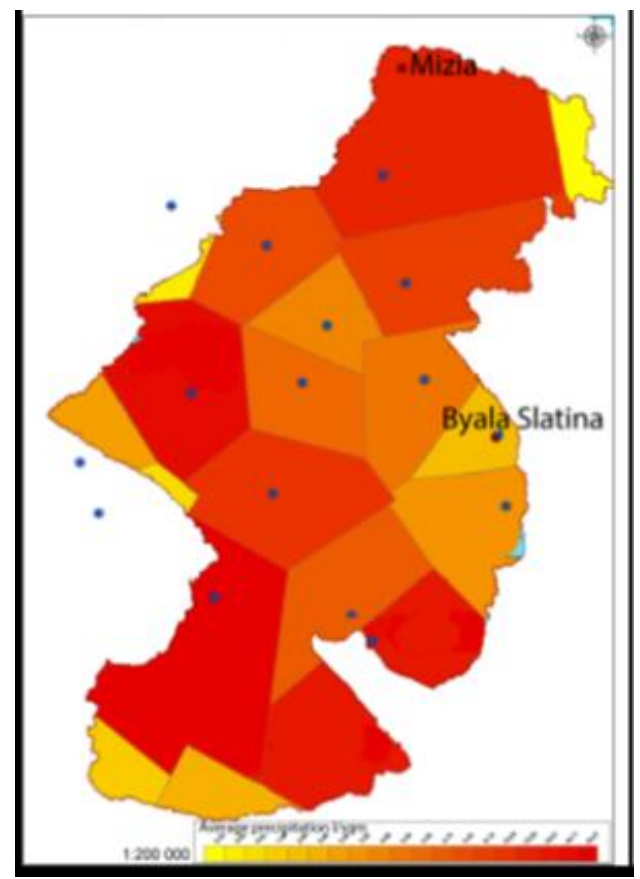

Figure 6: Territorial distribution of rainfall/precipitation in the Skat catchment area for the period 31.07.2014-2.08.2014 
Calculation of the surface water runoff

According to equation (2), the runoff is calculated for the individual sub-basins. (Fig. 7) The formed volume of the high wave, originating from the Skat River at the town of Mizia, is 74.3 million $\mathrm{m} 3$ and the formed maximum runoff - $587 \mathrm{~m} 3 / \mathrm{s}$.

\section{CONCLUSION}

The SCS curve number method is a simple, widely used and efficient method for determining the approximate amount of runoff from a rainfall even in a particular area. Perceived advantages of the method are: (1) its simplicity; (2) its predictability; (3) its stability; (4) its reliance on only one parameter; and (5) its responsiveness to major. runoff-producing watershed properties (soil type, land use/treatment, surface condition, and antecedent condition).

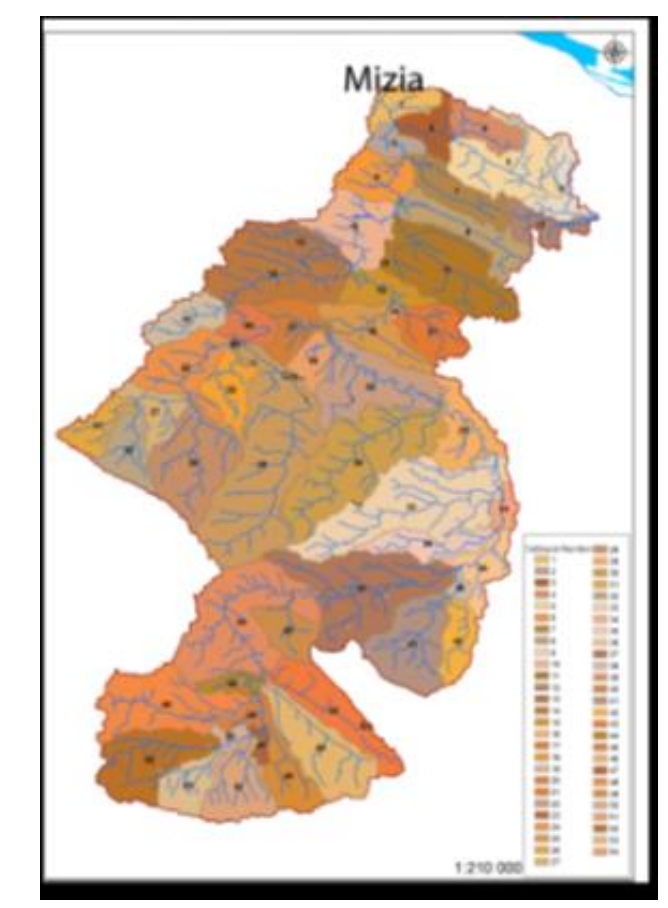

Figure 7: Sub-basins of the Skat river catchment

Perceived disadvantages are: (1) its marked sensitivity to curve number; (2) the absence of clear guidance on how to vary antecedent condition; (3) the method's varying accuracy for different biomes; (4) the absence of an explicit provision for spatial scale effects; and (5) the fixing of the initial abstraction ratio at $\lambda=0.2$, preempting a regionalization based on geologic and climatic setting.

\section{REFERENCES}

[1] Hydrology National Engineering Handbook, United States, Department of Agriculture Natural Resources Conservation Service, Part 630;

[2] Information from the NIMH and the Hail Control Executive Agency.(In Bulgarian);

[3] Map of the restored property, current 2013. Provided by the Ministry of Agriculture, Food and Forestry (In Bulgarian);

[4] Soil map (1:200 000), Provided by the Ministry of Agriculture, Food and Forestry 
[5] Bosznay, M. "Generalization of SCS curve number method." J. Irrig. and Drain. Engrg., ASCE, 115(1), 139-144. 1989;

[6] Hjelmfelt, A. T. "Investigation of curve number procedure." J. Hydr. Engrg., ASCE, 117(6), 725-737. 1991;

[7] Hawkins, R. H. "Asymptotic determination of runoff curve numbers from data." J. Irrig. and Drain. Engrg., ASCE, 119(2), 334-345. 1993;

[8] Steenhuis, T. S., Winchell, M., Rossing, J., Zollweg, J., and Walter, M. F. "SCS runoff equation revisited for variable-source runoff areas." J. Irrig. and Drain. Engrg., ASCE, 121(3), 234-238. 1995. 